\title{
Current opinions and practices for the management of acute appendicitis: an international survey
}

\author{
Patrick Anthony Boland ${ }^{1}$ (D) Noel E. Donlon ${ }^{2,3} \cdot$ Michael E. Kelly $^{2} \cdot$ Timothy Nugent $^{2} \cdot$ Ross Free $^{2} \cdot$ Peadar Waters $^{4}$. \\ Peter Neary ${ }^{5} \cdot$ Emanuele Rausa $^{6} \cdot$ David Proud $^{7} \cdot$ Claire L. Donohoe ${ }^{2} \cdot$ Kevin M. Barry ${ }^{1,8} \cdot$ John V. Reynolds $^{2,3}$
}

Received: 14 June 2020 / Accepted: 13 August 2020 / Published online: 27 August 2020

(C) Royal Academy of Medicine in Ireland 2020

\begin{abstract}
Background In recent decades the management of acute appendicitis has evolved significantly. Improved access to early imaging and better clinical scoring algorithms have resulted in less negative appendicectomy rates. In addition, non-operative management has become increasingly utilized. The aim of this study was to assess the variability of management of acute appendicitis globally.

Methods This was a multi-national targeted survey of general surgeons across 39 countries. A structured set of questions was utilized to delineate nuances between management styles of consultants and trainees. Opinions on the pathological diagnosis of appendicitis, acceptable negative appendicectomy rates, and the role of non-operative treatment of appendicitis (NOTA) were surveyed.

Results A total of 304 general surgeons responded to this survey, $42 \%$ of which were consultants/attendings. Sixty-nine percent advocated that a histologically normal appendix was the most appropriate definition of a negative appendicectomy, while 29\% felt that anything other than inflammation, necrosis, gangrene, or perforation was more appropriate. Forty-three percent felt that negative appendicectomy rates should be less than $10 \%$, with $41 \%$ reporting that their own negative appendicectomy rate was $<$ $5 \%$. Interestingly, only $17 \%$ reported routinely using NOTA for uncomplicated appendicitis, with one-fifth stating that they would undergo NOTA if they themselves had uncomplicated appendicitis.

Conclusion This study represents the largest sampling of management strategies for acute appendicitis. It shows substantial global heterogeneity between clinicians regarding what constitutes a negative appendicectomy as well as the appropriateness of non-operative management.
\end{abstract}

Keywords Appendicitis $\cdot$ Negative appendicectomy $\cdot$ Non-operative treatment of appendicitis $\cdot$ Surgical management

\section{Introduction}

Appendicitis is the most common cause of emergency surgical admission worldwide with an incidence of 86 cases per

Patrick Anthony Boland and Noel E. Donlon contributed equally to this work.

\section{Patrick Anthony Boland}

patrick.boland.1@ucdconnect.ie

Mayo University Hospital, Castlebar, Ireland

2 Department of Surgery, St. James' Hospital, Dublin 8, Ireland

3 School of Medicine, Trinity College Dublin, Dublin, Ireland

4 Department of Surgery, Royal Brisbane and Women's Hospital, Herston, Australia
100,000 per year [1]. Appendicectomy has been a standard treatment since McBurney described the procedure in 1889 [2, $3]$. Numerous developments have occurred in the management of acute appendicitis over the last hundred years

5 Department of Surgery, University Hospital Waterford, Waterford, Ireland

6 Department of General Surgery, Papa Giovanni XXIII Hospital, Bergamo, Italy

7 Department of Surgery, Austin Hospital, Melbourne, Australia

8 Discipline of Surgery, National University of Ireland, Galway, Ireland 
including laparoscopy, image guided drainage, widespread availability of computed tomography (CT), and various scoring algorithms. More recently, the use of non-operative treatment of appendicitis (NOTA) has been promoted. However, this is not a new concept, having been first used successfully among submarine sailors during the Second World War [4]. Recent studies have shown it as a viable treatment option in the hospital setting and as both safe and effective [5-9]. However, there remains resistance around its routine use and reported recurrence rates of $>20 \%$ in 1 year and almost $40 \%$ at 5 years [10-12].

Historically, negative appendicectomy rates (NAR) have been as high as $15-25 \%$ [13-16]. But with better use of radiological imaging, negative appendicectomy rates have significantly reduced $[17,18]$. Improvements in imaging modalities and more widespread use have also facilitated the selection of patients in whom a NOTA approach is possible. However, it is not yet clear if NOTA is a regular management approach by the majority of surgeons across the world. Furthermore, while computed tomography (CT) scanning is widely available, some have cautioned against an overreliance on CT imaging [18] with the Right Iliac Fossa Pain Treatment (RIFT) Study identifying significant differences in approaches to diagnostic modalities across its treatment arms. The aim of this study was to assess the variability of management options for acute appendicitis among general surgeons.

\section{Methods}

A standardized questionnaire was created and circulated among several surgical societies and trainee groups (Royal College of Surgeons in Ireland; Royal College of England; College of Physicians \& Surgeons in Pakistan; College of Surgeons Academy of Medicine Malaysia; European Society of Coloproctology; and British, Australian and Italian surgical trainee groups). Participants received an electronic invitation to contribute to the survey (freeonlinesurveys.com). This provided a secure method to collect and store the data, as well as edit or add questions if required.

Demographic questions included staff grade, gender, age, years in clinical practice, and their geographical location. Questions then focused on the surgeons' perspective on acute appendicitis diagnosis including the following: how to correctly define a negative appendicectomy, histopathological findings that should be classified as a negative appendicectomy, acceptable negative appendicectomy rates, and an estimate of their own negative appendicectomy rate. In addition, the usefulness of clinical, biochemical, and radiological imaging in the diagnosis of appendicitis were assessed. Lastly, participants were questioned on management options for acute appendicitis including non-operative treatment, removal of macroscopically normal appendix, and the role of interval appendicectomy following NOTA management. Data was stored on the freeonlinesurveys.com account and the website functions facilitated analysis. The data was also exported to SPSS facilitating analysis.

\section{Results}

\section{Demographics}

From February 2019 to October 2019, there were 304 responses in total, from surgeons across 39 countries (Fig. 1). Of these, $128(42.1 \%)$ were consultant/attending grade, and $176(57.9 \%)$ were registrars, specialist registrars, or fellows. Two hundred twenty-one $(72.7 \%)$ were male. With regard to clinical experience, the vast majority $(85.5 \%, n=260 / 304)$ had at least 5 years of clinical experience (Table 1).

\section{Opinions on negative appendicectomy}

Respondents were asked how a negative appendicectomy should be defined. Of these, $69.4 \%(n=211 / 304)$ were of the opinion that a "histologically normal appendix" was correct, versus $28.6 \%(n=87 / 304)$ who felt that a histological finding of anything other than inflammation, necrosis, perforation or gangrene was more appropriate. Participants were also asked if specific histological findings should be considered negative, with little agreement on this subject: lymphoid hyperplasia $(51.6 \%, n=157 / 304)$, fibrosis $(49.3 \%, n=150 /$ $304)$, atrophy $(59.9 \%(n=182 / 304)$, and Enterobius vermicularis $(32.2 \%, n=98 / 304)$. The majority felt that a NAR of $<10 \%$ was acceptable $(77.3 \%, n=235 / 304)$, while a small proportion believing a $>20 \%$ rate was appropriate $(1.6 \%, n=5 / 304)$. When asked to estimate their own NAR, the results were similar; $79.9 \%(n=243 / 304)$ reported rates $<$ $10 \%$, and $2.6 \%(n=8 / 304)$ reported $>20 \%$ (Table 2$)$.

\section{Diagnosis and operative management of appendicitis}

Most respondents did not find the Alvarado score to be beneficial for use in either the paediatric $(55.9 \%, n=170 / 304)$ or adult $(58.2 \%, n=177 / 304)$ populations. The majority did advocate the routine use of ultrasound (US) imaging in both female $(88.2 \%, n=255 / 289)$ and male $(62.6 \%, n=181 / 289)$ pediatric patients. However, less agreed with routine use of CT to out-rule appendicitis in adults. Only $31.7 \%(n=92 / 290)$ agreed with its use in females, while a lower proportion of $20.7 \%(n=60 / 290)$ advocated for it in males. In general, three quarters of those surveyed agreed with the removal of a macroscopically normal appendix on laparoscopy, for both males $(74.8 \%, n=217 / 290)$ and females $(76.8 \% n=222 / 289)$. Interestingly, $20 \%$ also recommend continuing antibiotic 


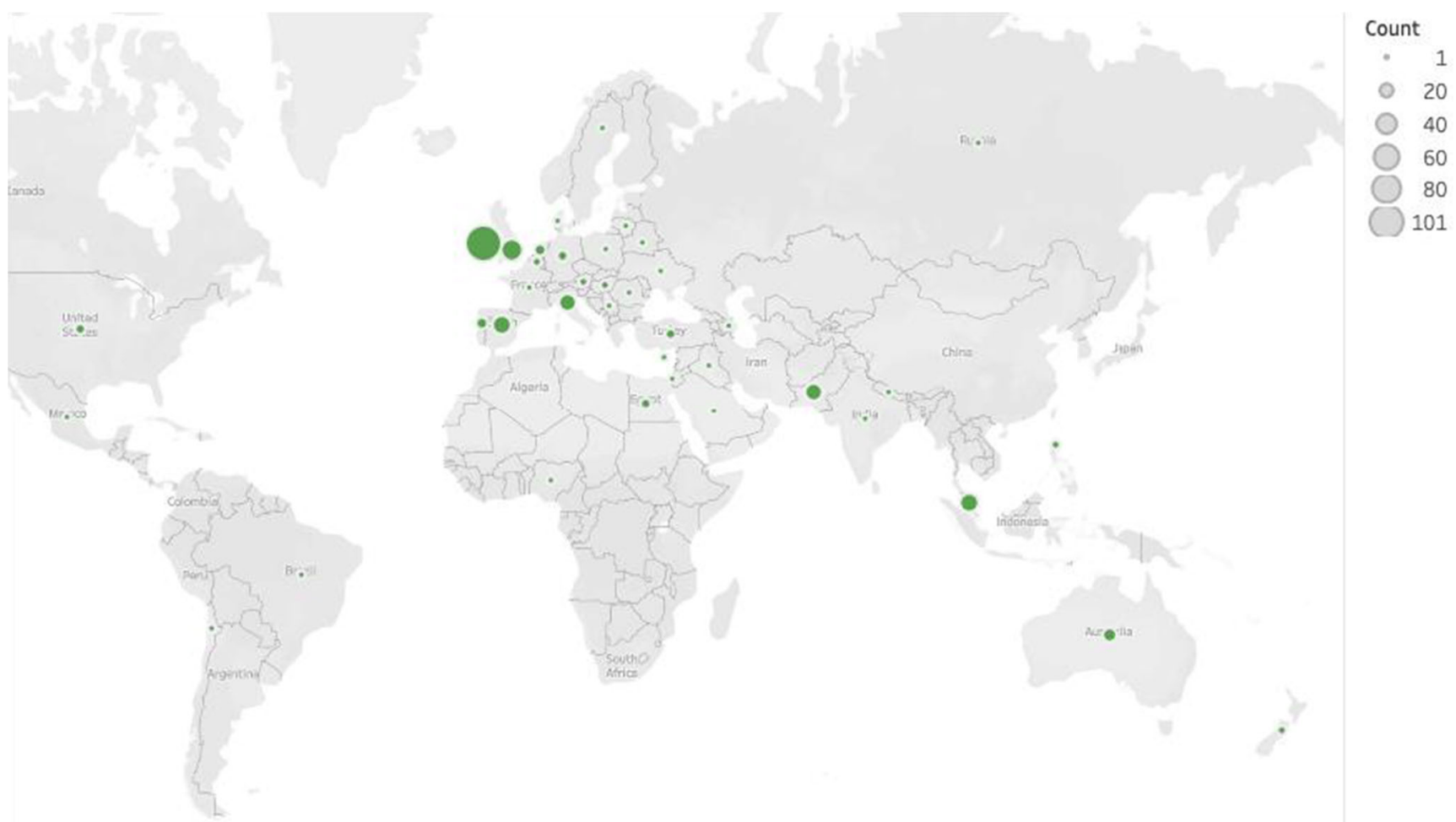

Fig. 1 Geographical location of participants

therapy post-operatively for acute uncomplicated appendicitis $(21.4 \%, n=62 / 290)$ (Table 3).

\section{Opinions on non-operative treatment of appendicitis}

A small majority of surgeons agreed that NOTA is a viable routine management option $(55.2 \%, n=160 / 290)$. A significantly lower proportion routinely utilize NOTA in their practice $(17.3 \%, n=50 / 290)$. Notably, a small percentage would opt for NOTA if they themselves had acute uncomplicated

Table 1 Demographics of respondents

\begin{tabular}{ll} 
Demographic & \\
Consultant & $115(37.8 \%)$ \\
Attending & $13(4.3 \%)$ \\
Registrar/specialist registrar & $119(39.1 \%)$ \\
Resident & $40(13.2 \%)$ \\
Male:female & $221: 83$ \\
Age & $35(25-68)$ \\
Years of clinical practice & \\
$0-4$ years & $44(14.5 \%)$ \\
$5-9$ years & $124(40.8 \%)$ \\
$10-14$ years & $75(24.7 \%)$ \\
$15-19$ years & $32(10.5 \%)$ \\
$>20$ years & $29(9.5 \%)$ \\
\hline
\end{tabular}

appendicitis $(22.4 \%, n=65 / 290)$. Almost one-third advocated for interval appendicectomy following NOTA for uncomplicated appendicitis $(32.1 \%, n=93 / 290)$. Twice as many respondents felt that interval appendicectomy was appropriate following complicated appendicitis $(70.7 \%, n=205 / 290)$ (Table 4).

\section{Discussion}

This study represents the largest worldwide survey of surgeons on the management of acute appendicitis and provides an interesting insight to current opinions and practices. The survey is both diverse, with 39 countries surveyed, and the vast majority of respondents had at least 5 years of clinical experience. Interestingly, there was little agreement among participants on how to define a negative appendicectomy. Despite this, the majority ( $>75 \%)$ feel that with improved technology, negative appendicectomy rates should be $<$ $10 \%$. In general, the Alvarado score is not trusted, while most surgeons advocate for routine ultrasound in pediatric populations, particularly in females. Conversely, the participants did not feel that routine $\mathrm{CT}$ was appropriate in the adult population. Approximately $75 \%$ would remove a macroscopically normal appendix in patients with right iliac fossa (RIF) pain with no obvious cause, and only half believe that NOTA is a viable treatment option. 
Table 2 Negative appendicectomy

\begin{tabular}{|c|c|c|}
\hline Question & Answer & Total \\
\hline \multirow[t]{3}{*}{ Which definition of a negative appendicectomy is the most appropriate? } & Histologically normal appendix & $69.6 \%(n=211 / 303)$ \\
\hline & $\begin{array}{l}\text { Histological findings of anything other than } \\
\text { inflammation, necrosis perforation, or } \\
\text { gangrene }\end{array}$ & $28.7 \%(n=87 / 303)$ \\
\hline & Other & $1.7 \%(n=5 / 303)$ \\
\hline \multirow[t]{2}{*}{ Should lymphoid hyperplasia be classified as a negative appendicectomy? } & Yes & $51.6 \%(n=157 / 304)$ \\
\hline & No & $48.6 \%(n=147 / 304)$ \\
\hline \multirow[t]{2}{*}{ Should fibrosis be classified as a negative appendicectomy? } & Yes & $49.3 \%(n=150 / 304)$ \\
\hline & No & $50.7 \%(n=154 / 304)$ \\
\hline \multirow[t]{2}{*}{ Should atrophy be classified as a negative appendicectomy? } & Yes & $59.9 \%(n=182 / 304)$ \\
\hline & No & $40.1 \%(n=122 / 304)$ \\
\hline \multirow[t]{2}{*}{ Should Enterobius vermicularis be classified as a negative appendicectomy? } & Yes & $32.2 \%(n=98 / 304)$ \\
\hline & No & $67.8 \%(n=206 / 304)$ \\
\hline \multirow[t]{6}{*}{ What is an acceptable negative appendicectomy rate? } & $<5 \%$ & $33.9 \%(n=103 / 304)$ \\
\hline & $5.1-10 \%$ & $43.4(n=132 / 304)$ \\
\hline & $10.1-15 \%$ & $14.5 \%(n=44 / 304)$ \\
\hline & $15.1-20 \%$ & $6.6 \%(n=20 / 304)$ \\
\hline & $20.1-25 \%$ & $0.7 \%(n=2 / 304)$ \\
\hline & $>25 \%$ & $1 \%(n=3 / 304)$ \\
\hline \multirow[t]{6}{*}{ What is your approximate negative appendicectomy rate? } & $<5 \%$ & $41.1 \%(n=125 / 304)$ \\
\hline & $5.1-10 \%$ & $38.8 \%(n=118 / 304)$ \\
\hline & $10.1-15 \%$ & $13.8 \%(n=42 / 304)$ \\
\hline & $15.1-20 \%$ & $3.6 \%(n=11 / 304)$ \\
\hline & $20.1-25 \%$ & $1.3 \%(n=4 / 304)$ \\
\hline & $>25 \%$ & $1.3 \%(n=4 / 304)$ \\
\hline
\end{tabular}

The survey's participants demonstrate optimistic aspirations around negative appendicectomy rates, with approximately one-third suggesting that it should be kept below 5\% and three-quarters suggesting that it should be kept below $10 \%$. Such a target may be achievable with correct utilization of CT imaging and scoring algorithms [17, 19, 20]. However, the majority of participants do not support routine use of CT imaging for diagnosis of appendicitis and do not find the
Alvarado score useful. The lack of trust for the Alvarado score is particularly notable. Algorithms such as the Alvarado and Appendicitis Inflammatory Response (AIR) score are derived from small retrospective studies and, to date, are poorly validated [21-23]. With this in mind, it is not surprising that such scoring systems are not therefore widely employed. The RIFT audit advocated for the routine scoring of adults presenting with acute RIF pain or suspected appendicitis using the

Table 3 Diagnostics

\begin{tabular}{|c|c|c|}
\hline Question & Yes & No \\
\hline Do you find the Alvarado score useful in pediatric patients? & $44.1 \%(n=134 / 304)$ & $55.9 \%(n=170 / 304)$ \\
\hline Do you find the Alvarado score useful in adult patients? & $41.8 \%(n=127 / 304)$ & $58.2 \%(n=177 / 304)$ \\
\hline Do you use US imaging in diagnosing appendicitis in pediatric females? & $88.2 \%(n=255 / 289)$ & $11.8 \%(n=34 / 289)$ \\
\hline Do you use US imaging in diagnosing appendicitis in pediatric males? & $62.6 \%(n=181 / 289)$ & $37.4 \%(n=108 / 289)$ \\
\hline Should CT be routinely used to out rule appendicitis in males $>18$ years? & $20.7 \%(n=60 / 290)$ & $79.3 \%(n=230 / 290)$ \\
\hline Should CT be routinely used to out rule appendicitis in females $>18$ years? & $31.7 \%(n=92 / 290)$ & $68.3 \%(n=198 / 290)$ \\
\hline $\begin{array}{l}\text { During laparoscopy, should a macroscopically normal appendix be removed in a male in which no other } \\
\text { cause for pain is identified? }\end{array}$ & $74.8 \%(n=217 / 290)$ & $25.2 \%(n=73 / 290)$ \\
\hline $\begin{array}{l}\text { During laparoscopy. Should a macroscopically normal appendix be removed in a female in which no other } \\
\text { cause for pain is identified? }\end{array}$ & $76.8 \%(n=222 / 289)$ & $23.2 \%(n=67 / 222)$ \\
\hline Do you continue antibiotics post-operatively in uncomplicated appendicitis? & $21.4 \%(n=62 / 290)$ & $78.6 \%(n=228 / 290)$ \\
\hline
\end{tabular}


Table 4 Non-operative treatment of appendicitis

\begin{tabular}{lll}
\hline Question & Yes & No \\
\hline $\begin{array}{l}\text { Is NOTA a viable option for uncomplicated appendicitis in } \\
\text { otherwise healthy patients? }\end{array}$ & $55.2 \%(n=160 / 290)$ & $44.8 \%(n=130 / 290)$ \\
$\begin{array}{c}\text { Do you routinely practice NOTA for uncomplicated } \\
\text { appendicitis in otherwise healthy patients? }\end{array}$ & $17.3 \%(n=50 / 290)$ & $82.8 \%(n=240 / 290)$ \\
$\begin{array}{l}\text { If you personally developed uncomplicated appendicitis, } \\
\text { would you prefer NOTA over operative intervention? }\end{array}$ & $22.4 \%(n=65 / 290)$ & $77.6 \%(n=225 / 290)$ \\
$\begin{array}{c}\text { Would you perform an interval appendicectomy in a patient } \\
\text { with uncomplicated appendicitis who underwent NOTA? }\end{array}$ & $32.1 \%(n=93 / 290)$ & $67.9 \%(n=197 / 290)$ \\
$\begin{array}{c}\text { Would you perform an interval appendicectomy in a patient } \\
\text { with complicated appendicitis who underwent NOTA? }\end{array}$ & $70.7 \%(n=205 / 290)$ & $29.3 \%(n=85 / 290)$ \\
\hline
\end{tabular}

appropriate risk prediction model with a mobile, tablet, and desktop compatible web application developed to support the calculation [24].

Approximately $50 \%$ of general surgeons view NOTA as a viable management option. However, the vast majority do not practice NOTA and would not personally choose it over appendicectomy. This is potentially due to the high rate of recurrence. The recent 7-year follow-up of the APPAC trial showed higher patient satisfaction in the operative group than those treated conservatively with antibiotics [25]. It is important to note that this survey was undertaken prior to the global COVID-19 pandemic. Since its onset, conservative management has been advised where possible, in an attempt to mitigate potential risk to staff and patients alike [26, 27]. A recent survey of Irish trainees and consultants showed that $76 \%$ of participants changed their practice to predominantly NOTA. The majority (74\%) obtained CT at presentation. However, it must be noted that $83 \%$ would return to operative management after the COVID-19 pandemic. This same study also studied 18 patients treated for acute appendicitis in Ireland during this period, with $11(61 \%)$ undergoing NOTA. The median length of stay was 3.5 days for NOTA vs 2 days for operative management. At 1 week post-discharge, $54 \%$ in the NOTA group had ongoing discomfort, $63 \%$ stated that they would have chosen appendicectomy, and $45 \%$ wanted to pursue interval appendicectomy [28].

With a lower patient satisfaction, and the apparent mistrust among surgeons illustrated in this study, should health professionals be advocating for NOTA treatment at all? Further prospective studies will delineate if it is a sustainable management option.

\section{Conclusion}

There is significant heterogeneity among surgeons regarding on how to correctly define a negative appendicectomy and the role of routine radiological imaging. Furthermore, there is a considerable debate around the non-operative treatment of appendicitis, and the majority of respondents do not routinely use NOTA within their practice.

Data availability Survey data held on freeonlinesurveys.com. Available at request.

\section{Compliance with ethical standards}

Conflict of interest The authors declare that they have no conflict of interest.

Ethics approval Survey of expert opinion. Not applicable.

Consent to participate Consent obtained when email sent to participants.

Consent for publication Participants informed prior to participation that results would be published.

Code availability Not applicable.

\section{References}

1. Körner H, Söndenaa K, Söreide JA, et al. (1997) Incidence of acute nonperforated and perforated appendicitis: age-specific and sexspecific analysis. World J Surg 21(3):313-317

2. Stewart B, Khanduri P, McCord C, et al. (2014) Global disease burden of conditions requiring emergency surgery. Br J Surg 101(1):e9-e22

3. Charles M (1889) Experience with early operative interference in cases of disease of the vermiform appendix. NY Med J, pp 492-538

4. Campbell MR, Johnston SL III, Marshburn T, et al. (2004) Nonoperative treatment of suspected appendicitis in remote medical care environments: implications for future spaceflight medical care. J Am Coll Surg 198(5):822-830

5. Styrud J, Eriksson S, Nilsson I, et al. (2006) Appendectomy versus antibiotic treatment in acute appendicitis. A prospective multicenter randomized controlled trial. World J Surg 30(6):1033-1037

6. Eriksson S, Granström L (1995) Randomized controlled trial of appendicectomy versus antibiotic therapy for acute appendicitis. Br J Surg 82(2):166-169

7. Vons C, Barry C, Maitre S, et al. (2011) Amoxicillin plus clavulanic acid versus appendicectomy for treatment of acute uncomplicated appendicitis: an open-label, non-inferiority, randomised controlled trial. Lancet 377(9777):1573-1579 
8. Svensson JF, Patkova B, Almström M, et al. (2015) Nonoperative treatment with antibiotics versus surgery for acute nonperforated appendicitis in children: a pilot randomized controlled trial. Ann Surg 261(1):67-71

9. Salminen P, Paajanen H, Rautio T, et al. (2015) Antibiotic therapy vs appendectomy for treatment of uncomplicated acute appendicitis: the APPAC randomized clinical trial. JAMA 313(23):23402348

10. Salminen P, Tuominen R, Paajanen H, et al. (2018) Five-year follow-up of antibiotic therapy for uncomplicated acute appendicitis in the APPAC randomized clinical trial. JAMA 320(12):1259-1265

11. Sallinen V, Akl EA, You JJ, et al. (2016) Meta-analysis of antibiotics versus appendicectomy for non-perforated acute appendicitis. Br J Surg 103(6):656-667

12. Podda M, Cillara N, di Saverio S, et al. (2017) Antibiotics-first strategy for uncomplicated acute appendicitis in adults is associated with increased rates of peritonitis at surgery. A systematic review with meta-analysis of randomized controlled trials comparing appendectomy and non-operative management with antibiotics. Surgeon 15(5):303-314

13. Detmer DE, Nevers LE, Sikes ED (1981) Regional results of acute appendicitis care. JAMA 246(12):1318-1320

14. Wagner PL, Eachempati SR, Soe K, et al. (2008) Defining the current negative appendectomy rate: for whom is preoperative computed tomography making an impact? Surgery 144(2):276-282

15. Lewis FR et al (1975) Appendicitis. A critical review of diagnosis and treatment in 1,000 cases. Arch Surg 110(5):677-684

16. Seetahal SA, Bolorunduro OB, Sookdeo TC, et al. (2011) Negative appendectomy: a 10-year review of a nationally representative sample. Am J Surg 201(4):433-437

17. Raja AS, Wright C, Sodickson AD, et al. (2010) Negative appendectomy rate in the era of CT: an 18-year perspective. Radiology 256(2):460-465

18. Flum DR, McClure TD, Morris A, Koepsell T (2005) Misdiagnosis of appendicitis and the use of diagnostic imaging. J Am Coll Surg 201(6):933-939
19. Petrosyan M, Estrada J, Chan S, et al. (2008) CT scan in patients with suspected appendicitis: clinical implications for the acute care surgeon. Eur Surg Res 40(2):211-219

20. Antevil JL, Rivera L, Langenberg BJ, et al. (2006) Computed tomography-based clinical diagnostic pathway for acute appendicitis: prospective validation. J Am Coll Surg 203(6):849-856

21. Alvarado A (1986) A practical score for the early diagnosis of acute appendicitis. Ann Emerg Med 15(5):557-564

22. Andersson M, Andersson RE (2008) The appendicitis inflammatory response score: a tool for the diagnosis of acute appendicitis that outperforms the Alvarado score. World J Surg 32(8):1843-1849

23. Kularatna M, Lauti M, Haran C, et al. (2017) Clinical prediction rules for appendicitis in adults: which is best? World J Surg 41(7): 1769-1781

24. Bhangu A (2020) Evaluation of appendicitis risk prediction models in adults with suspected appendicitis. Br J Surg 107(1):73-86

25. Sippola S, et al (2020) Quality of life and patient satisfaction at 7year follow-up of antibiotic therapy vs appendectomy for uncomplicated acute appendicitis: a secondary analysis of a randomized clinical trial. JAMA Surg

26. Brat GA, Hersey S, Chhabra K, et al. (2020) Protecting surgical teams during the COVID-19 outbreak: a narrative review and clinical considerations. Ann Surg

27. Ross GL (2020) Clinical characteristics and outcomes of patients undergoing surgeries during the incubation period of COVID-19 infection. What are the implications for the commencement of elective surgery? EClinicalMedicine 100385

28. Kelly ME, Murphy E, Bolger JC, Cahill RA (2020) COVID-19 and the treatment of acute appendicitis in Ireland: a new era or shortterm pivot? Color Dis 22(6):648-649

Publisher's note Springer Nature remains neutral with regard to jurisdictional claims in published maps and institutional affiliations. 